\title{
Prognostic implications of Fibroblast growth factor receptor 1 (FGFR1) gene amplification and protein overexpression in hypopharyngeal and laryngeal squamous cell carcinoma
}

Eun Kyung Kim ${ }^{1}$, Yoon Ah Cho ${ }^{2,3}$, Yoon Woo Koh ${ }^{4}$, Hyang Ae Shin ${ }^{5}$, Byoung Chul Cho ${ }^{6^{*+}}$ and Sun Och Yoon ${ }^{2^{*+}}$

\begin{abstract}
Background: The gene encoding fibroblast growth factor receptor 1 (FGFR1) is emerging as a therapeutic and prognostic biomarker in various cancer types, including head and neck squamous cell carcinoma (SCC). Here, we investigated the clinicopathologic implication of FGFR1 gene amplification and protein overexpression in hypopharyngeal and laryngeal SCC.
\end{abstract}

Methods: Fluorescence in situ hybridization and immunohistochemistry were performed to determine FGFR1 gene amplification and protein overexpression in 209 surgically resected cases.

Results: FGFR1 amplification observed in 8 (8/66, 12.1\%; 6 hypopharynx and 2 lanynx) patients and high FGFR1 expression in $21(21 / 199,10.6 \%)$ patients significantly correlated with lymph node metastasis and advanced pathological stages. FGFR1 amplification was also associated with worse disease-free survival in multivariate analysis (hazard ratio $=4.527, P=0.032$ ). High FGFR1 expression was more frequently observed, consistent with the worsening of the degree of histologic differentiation.

Conclusions: FGFR1 amplification may serve as an independent prognostic factor for disease-free survival in hypopharyngeal and laryngeal SCC. Aberrant FGFR signaling caused by FGFR1 gene amplification or protein overexpression may play a crucial role in the malignant evolution and progression of hypopharyngeal and laryngeal SCC, and offer novel therapeutic opportunities in patients with hypopharyngeal and laryngeal SCC that usually lack specific therapeutic targets.

Keywords: Fibroblast growth factor receptor 1 (FGFR1), Amplification, Fluorescence in situ hybridization, Immunohistochemistry, Hypopharynx, Larynx, Squamous cell carcinoma

\footnotetext{
* Correspondence: CBC1971@yuhs.ac; soyoon@yuhs.ac

†Byoung Chul Cho and Sun Och Yoon contributed equally to this work. ${ }^{6}$ Division of Medical Oncology, Yonsei Cancer Center, Yonsei University College of Medicine, 50-1 Yonsei-ro, Seodaemun-gu, Seoul 03722, South Korea

${ }^{2}$ Department of Pathology, Severance Hospital, Yonsei University College of Medicine, 50-1 Yonsei-ro, Seodaemun-gu, Seoul 03722, South Korea Full list of author information is available at the end of the article
}

(c) The Author(s). 2020 Open Access This article is licensed under a Creative Commons Attribution 4.0 International License, which permits use, sharing, adaptation, distribution and reproduction in any medium or format, as long as you give appropriate credit to the original author(s) and the source, provide a link to the Creative Commons licence, and indicate if changes were made. The images or other third party material in this article are included in the article's Creative Commons licence, unless indicated otherwise in a credit line to the material. If material is not included in the article's Creative Commons licence and your intended use is not permitted by statutory regulation or exceeds the permitted use, you will need to obtain permission directly from the copyright holder. To view a copy of this licence, visit http://creativecommons.org/licenses/by/4.0/ The Creative Commons Public Domain Dedication waiver (http://creativecommons.org/publicdomain/zero/1.0/) applies to the data made available in this article, unless otherwise stated in a credit line to the data. 


\section{Background}

Head and neck squamous cell carcinoma (HNSCC) arises from the squamous mucosa of the upper aerodigestive tract, which comprises the nasal cavity, paranasal sinus, oral cavity, nasopharynx, oropharynx, hypopharynx, and larynx. These distinct anatomic subsites contribute to the morphological, biological, and etiological heterogeneities of HNSCC. Cigarette smoking and alcohol consumption are the most common risk factors, especially for hypopharyngeal and laryngeal SCC [1, 2], while infection with high-risk human papilloma virus (HPV) has also been recognized as a risk factor associated with oropharyngeal SCC [3]. Recent studies have shown that HPV-positive SCC, mainly oropharyngeal SCC, exhibits significantly favorable survival outcomes [4-6]. However, SCCs of the hypopharynx and larynx, the second most common respiratory tract cancer after lung cancer, that represent HPV-negative HNSCCs are related to little improvement in patient outcomes despite multidisciplinary treatments because of frequent locoregional recurrences, distant metastases, and second primary tumors $[7,8]$.

The Cancer Genome Atlas (TCGA) has recently identified potentially targetable somatic genomic alterations based on HPV infection status, smoking, and primary tumor sites in HNSCC [9]. HPV-negative tumors are characterized with recurrent focal amplifications in receptor tyrosine kinases and fibroblast growth factor receptor 1 (FGFR1; 10\% frequency) is the second most commonly observed gene after EGFR (15\% frequency). The gene encoding FGFR1 is located on chromosome 8p11.23 and encodes tyrosine kinase family, which plays crucial roles in cancer development. This gene is dysregulated by amplification, point mutation, translocation, and overexpression in various cancers [10]. These aberrant FGFR1 alterations, in general, lead to gain-offunction characteristics and constitutively activate the downstream RAS/mitogen-activated protein kinase (MAPK), PI3K/protein kinase B (AKT), and Janus kinase (JAK)/signal transducer and activator of transcription (STAT) signaling pathways [11]. In previous studies of HNSCC, FGFR1 amplification has been reported in 3 to $17 \%$ of cases, and FGFR1 protein overexpression has been identified in about $11-82 \%$ of cases [12-18]. However, they presented conflicting results for FGFR1 as a prognostic biomarker. In addition, most of the studies have been conducted on the whole HNSCCs showing biological heterogeneity, and site-specific studies have been rarely performed on SCC, especially in SCCs of hypopharynx and larynx, which represent the prevalent subsites of HPV-negative SCC [13-19]. Therefore, more evidence is needed for the prognostic or predictive role of FGFR1 in HNSCC of hypopharynx and larynx.
As a predictive marker for drug response, FGFR1 has been identified in preclinical or clinical studies of lung SCC or breast cancer [19-21]. Recently, several nonselective or selective tyrosine kinase inhibitors suppressing FGFR1 expression, such as lucitanib (E3810), dovitinib (TKI258), ponatinib (AP24534), AZD4547, BGJ398, and TAS-120, have shown promising data or are currently being investigated in preclinical models and clinical trials on solid tumors, including HNSCC (NCT02706691, NCT02795156) [22, 23]. However, effective targeted therapies for advanced HNSCC are still limited to the antiEGFR monoclonal antibody, cetuximab, in HNSCC [24].

In this study, we evaluated FGFR1 gene amplification and protein overexpression and investigated its clinicopathologic and prognostic implications in hypopharyngeal and laryngeal SCC.

\section{Methods}

Patients and tissue samples

Archived formalin-fixed, paraffin-embedded (FFPE) specimens were obtained from patients with surgically resected primary hypopharyngeal and laryngeal SCC. The surgical resections, such as traditional or transoral robotic laryngopharyngectomy, excision, and cordectomy, were performed at Severance Hospital, Seoul, South Korea and National Health Insurance Service Ilsan Hospital, Goyang, South Korea, between 2005 and 2012 for curative aim. From the consecutive cases, 209 cases were selected when tumor tissues, clinical data (including smoking status), and survival data were available; patients received no preoperative treatment, and no clinicopathological evidences of distant metastasis were reported at the time of surgery. Relapsed patients were excluded. After surgery, some patients received adjuvant treatment, such as chemotherapy, radiotherapy, and concurrent chemoradiation therapy, based on the National Comprehensive Cancer Network $(\mathrm{NCCN})$ guidelines and clinical judgment.

Two pathologists (S.O.Y. and E.K.K.) evaluated the histologic features, including tumor location, size, grade, metastasis to regional lymph nodes, lymphovascular invasion, and perineural invasion, and confirmed the histopathologic diagnosis. Tumors were classified according to the eighth American Joint Committee on Cancer (AJCC) cancer system [25] and the World Health Organization system [2]. Clinical data were collected and reviewed as per patients' medical records. Smoking status was defined as follows; "Never smokers" are those who have smoked less than 100 cigarettes in their lifetime, "former smokers" are those who have quit smoking for more than 12 months, and "current smokers" are those who are currently smoking or who have quit smoking for less than 12 months [26]. Alcohol consumption status was assessed as pure alcohol consumption, 
calculated as gram per day according to the average amount, frequency, and type. "Heavy drinkers" were those who consumed more than $30 \mathrm{~g} /$ day, and those who drank less were defined as "social drinkers" [27]. The study was approved by the Institutional Review Board of Severance Hospital (4-2015-0954) and National Health Insurance Service Ilsan Hospital (NHIMC 2018-04-021).

\section{Tissue microarray (TMA) construction}

Sections of FFPE tissues were prepared and stained with hematoxylin and eosin. The representative areas of tumors were confirmed and selected to obtain a TMA under the microscope. One to three different representative areas per case were selected, and core tissues $(3 \mathrm{~mm}$ in diameter) were obtained from the individual FFPE blocks. Considering the possibility of heterogeneity, randomly selected 35 cases were stained on whole section slides.

\section{FGFR1 fluorescence in situ hybridization (FISH)}

We conducted the FISH assay on the TMAs using commercially available $F G F R 1$ probes that hybridized to the 8p12-8p11.23 region using the fluorophore, Spectrum Orange (red) and to the centromere region of chromosome 8 (CEP 8) using the fluorophore, Spectrum Green (Abbott Molecular, Abbott Park, IL) following the manufacturers' protocol. FISH results were interpreted by two expert evaluators (S.O.Y. and E.K.K.) without knowing the clinical information. Cells with sharp borders of nuclei, no signs of over-digestion, or non-overlapping nuclei were counted. Normal tissues including blood vessels, fibroblasts, or adjacent normal squamous epithelium served as internal positive controls. Tumor tissue was scanned for hot spots under $40 \times$ or $63 \times$ objective lens. Twenty contiguous tumor cell nuclei from three hot spots or random areas resulting in a total of $60 \mathrm{nu}-$ clei were individually evaluated under the $100 \times$ objective lens by counting red FGFR1 and green CEP8 signals. FGFR1 gene amplification was defined as 1) an FGFR1/ CEP8 ratio of at least 2 and the average number of FGFR1 signals per tumor cell nucleus of at least 4 or 2) an average number of FGFR1 signals per tumor cell nucleus of at least $6[15,28]$.

\section{FGFR1 immunohistochemistry (IHC)}

FGFR1 protein expression was evaluated with $\mathrm{IHC}$ using a rabbit polyclonal anti-FGFR1 antibody (Clone ab10646, 1: 1500 dilution, Abcam, Cambridge, UK) on 4- $\mu$ m TMA tissue sections on a Ventana Bench Mark XT Autostainer (Ventana Medical Systems, Tucson, AZ, USA). FGFR1 staining pattern (cytoplasmic, membranous, or nuclear) and intensity ( 0 , negative; 1 , weak; 2 , moderate; and 3 , strong), and the percentage of positively stained tumor cells $(0-100 \%)$ were evaluated. Staining pattern of normal squamous epithelial cells and stromal cells adjacent to or separated from tumors was compared to that of tumor cells. In addition, IHC was performed for Snail (dilution 1: 200; Invitrogen, Thermo Fisher Scientific, CA, USA) and Twist (dilution 1:200; Abcam, Cambridge, UK), which are transcription factors related to epithelial mesenchymal transition (EMT). IHC expression of FGFR1, Snail, and Twist was analyzed using the semi-quantitative $\mathrm{H}$-score method, which yields a possible score range of 0-300 obtained by multiplying the dominant intensity score with the percentage of positive tumor cells.

In total, 171 samples subjected to p16 IHC (a mouse monoclonal antibody, clone E0037, Ventana, AZ, USA) at the time of diagnosis were reviewed. p16 expression was scored as positive upon detection of at least $70 \%$ nuclear and cytoplasmic expression, with at least moderate to strong intensity [29].

\section{Statistical analysis}

The chi-square, Fisher's exact, independent-samples ttests, and bivariate correlation analysis were conducted to compare the clinicopathologic parameters among patients with FGFR1 gene amplification and other protein expression. Statistical significance was set at $P<0.05$ for all analyses. Patient survival rates were determined using the Kaplan-Meier method, and differences in survival rates were compared using the log-rank test. Diseasefree survival (DFS) was measured from the time of surgery until disease progression, and was defined as cancer recurrence, continuance of progressive disease without complete remission, or cancer-related death. Overall survival (OS) was calculated from the date of surgery to the date of death or last follow-up visit. Multivariate analysis was performed with the Cox proportional hazard model using several clinicopathologic parameters. All statistical analyses were performed with IBM SPSS 22 software for Windows (IBM Corp, Somers, New York).

\section{Results \\ Demographic characteristics of patients with hypopharyngeal and laryngeal SCC}

The clinical and pathological characteristics of 209 patients are summarized in Table 1. A total of 195 (93.3\%) patients were males and $14(6.7 \%)$ were females, with a median age of 64 years (range 30-88 years). The cohort comprised 54 patients with (25.8\%) hypopharyngeal SCC and 155 patients with $(74.2 \%)$ laryngeal SCC. The majority of patients $(n=186,89 \%)$ were current or former smokers, with a median smoking dosage of 30.0 packyears (range $0-100$ ). Furthermore, the majority of patients $(n=149,87.1 \%)$ were heavy drinkers. Histological analysis revealed that most SCCs $(n=187,89.5 \%)$ were well to moderately differentiated and revealed p16 IHC negativity $(n=149,87.1 \%)$, as evident from 171 cases 
Table 1 Demographic characteristics of hypopharynx and larynx squamous cell carcinoma

\begin{tabular}{|c|c|c|c|}
\hline Characteristics & $\begin{array}{l}\text { All patients } \\
\mathrm{n}(\%)\end{array}$ & Characteristics & $\begin{array}{l}\text { All patients } \\
\mathrm{n}(\%)\end{array}$ \\
\hline Total & $209(100)$ & & \\
\hline Age (years) & & pT-classification & \\
\hline Median (range) & $64.0(30-88)$ & pT1 & $71(34.0)$ \\
\hline$<65$ & $114(54.5)$ & pT2 & $58(27.8)$ \\
\hline$\geq 65$ & $95(45.5)$ & pT3 & $52(24.9)$ \\
\hline Gender & & pT4a & $28(13.4)$ \\
\hline Female & $14(6.7)$ & pN-classification & \\
\hline Male & $195(93.3)$ & pNO & $118(56.5)$ \\
\hline Primary sites & & pN1 & $13(6.2)$ \\
\hline Hypopharynx & $54(25.8)$ & $\mathrm{pN} 2$ & $26(12.5)$ \\
\hline Larynx & $155(74.2)$ & pN3 & $52(24.9)$ \\
\hline Smoking & & Pathological stage & \\
\hline Never smoker & $23(11.0)$ & Stage I & $60(28.7)$ \\
\hline Former smoker & $54(25.8)$ & Stage II & $29(13.9)$ \\
\hline Current smoker & $132(63.2)$ & Stage III & $32(15.3)$ \\
\hline Alcohol & & Stage IVA & $36(17.2)$ \\
\hline Non- or social- drinker & $45(20.1)$ & Stage IVB & $52(24.9)$ \\
\hline Heavy drinker & $167(79.9)$ & Adjuvant treatment & \\
\hline Histologic differentiation & & No & $89(42.6)$ \\
\hline Well differentiated & 64 (30.6) & Yes & $120(57.4)$ \\
\hline Moderately differentiated & $123(58.9)$ & Chemotherapy (C) & $0(0.0)$ \\
\hline Poorly differentiated & $22(10.5)$ & Radiation therapy (R) & $71(34.0)$ \\
\hline Lymphovascular invasion & & $C+R$ & $49(23.4)$ \\
\hline Absent & $163(78.0)$ & Recurrence & \\
\hline Present & $46(22.0)$ & No & $164(78.5)$ \\
\hline Perineural invasion & & Yes & $45(21.5)$ \\
\hline Absent & $178(85.2)$ & Local recurrence only & $23(51.1)$ \\
\hline Present & $31(14.8)$ & Distant recurrence & $22(48.9)$ \\
\hline Positive resection margin & & Disease-free survival & \\
\hline Absent & $155(74.2)$ & Mean (range; months) & $82.3(2-105)$ \\
\hline Present & $54(25.8)$ & Overall survival time & \\
\hline p16 status $(n=171)$ & & Mean (range; months) & $76.4(2-105)$ \\
\hline Negative & $149(87.1)$ & & \\
\hline Positive & $22(12.9)$ & & \\
\hline
\end{tabular}

with available p16 IHC data. Advanced pT classification (pT3 and pT4a; $n=80,38.3 \%$ ) and advanced pN classification, especially pN3b $(n=52,24.9 \%)$, were not uncommon. TNM stages were as follows: stage I in $28.7 \%$ cases, stage II in $13.9 \%$ cases, stage III in $15.3 \%$ cases, stage IVA in $17.2 \%$ cases, and stage IVB in $24.9 \%$ cases. Adjuvant treatment (concurrent chemoradiation therapy and radiation therapy) was provided to 120 (57.4\%) patients. During the observation period with a median follow-up time of 38.8 months, $21.5 \%(n=45)$ patients experienced recurrence. The mean DFS and OS rates for all patients were 82.3 months (range, $2-105$ months) and 76.4 months (2-105 months), respectively. The 5-year DFS and OS rates were 74.1 and $67.6 \%$, respectively.

\section{FGFR1 amplification status in hypopharyngeal and laryngeal SCC}

The FISH test was finally available for 66 cases, excluding cases with decalcified tissue, insufficient amounts of tumor cells, or poor signals on FISH tests. Of these, 8 
Table 2 The status of FGFR1 gene amplification and protein overexpression in patients with hypopharyngeal and laryngeal squamous cell carcinoma

\begin{tabular}{|c|c|c|c|c|c|c|}
\hline \multirow[t]{2}{*}{ Characteristics } & \multicolumn{2}{|c|}{ FGFR1 amplification, $n=66$} & \multirow{2}{*}{$\begin{array}{l}P \\
\text { value }\end{array}$} & \multicolumn{2}{|c|}{ FGFR1 high expression, $n=199$} & \multirow[t]{2}{*}{$P$ value } \\
\hline & Present, n (\%) & Absent, n (\%) & & Present, n (\%) & Absent, n (\%) & \\
\hline Total & $8(12.1)$ & $58(87.9)$ & & $21(10.6)$ & $178(89.4)$ & \\
\hline Primary sites & & & 0.015 & & & 0.307 \\
\hline Hypopharynx & $6(75.0)$ & $36(62.1)$ & & $6(28.6)$ & $47(26.4)$ & \\
\hline Larynx & $2(25.0)$ & $22(37.9)$ & & $15(71.4)$ & $131(73.6)$ & \\
\hline Gender & & & 0.771 & & & 0.145 \\
\hline Female & $0(0.0)$ & $2(3.4)$ & & $3(14.3)$ & $10(5.6)$ & \\
\hline Male & $8(100.0)$ & $56(96.6)$ & & $18(85.7)$ & $168(94.4)$ & \\
\hline Age (years) & & & 0.452 & & & 0.820 \\
\hline Median (range) & $68.0(55-73)$ & $63.0(42-88)$ & & $63.0(45-78)$ & $64.0(30-88)$ & \\
\hline$<65$ & $3(37.5)$ & $33(56.9)$ & & $12(57.1)$ & $95(53.4)$ & \\
\hline$\geq 65$ & $5(62.5)$ & $25(43.1)$ & & $9(42.9)$ & $83(46.6)$ & \\
\hline Smoking & & & 0.405 & & & 0.302 \\
\hline Never smoker & $2(25.0)$ & $7(12.1)$ & & $3(14.3)$ & $19(10.7)$ & \\
\hline Former smoker & $1(12.5)$ & $15(25.9)$ & & $6(28.6)$ & $45(25.3)$ & \\
\hline Current smoker & $5(62.5)$ & $36(62.1)$ & & $12(57.1)$ & $114(64.0)$ & \\
\hline Alcohol & & & 0.196 & & & 0.778 \\
\hline Non- or social- drinker & $0(0.0)$ & $13(22.4)$ & & $5(23.8)$ & $37(20.8)$ & \\
\hline Heavy drinker & $8(100.0)$ & $45(77.6)$ & & $16(76.2)$ & $141(79.2)$ & \\
\hline p16 status & & & 0.551 & & & 0.697 \\
\hline Negative & $7(87.5)$ & $47(81.0)$ & & $14(82.4)$ & $131(88.5)$ & \\
\hline Positive & $1(12.5)$ & $11(19.0)$ & & $3(17.6)$ & $17(11.5)$ & \\
\hline Unknown & - & & & & & \\
\hline Histologic differentiation & & & 0.355 & & & $<0.001$ \\
\hline Well differentiated & $2(25.0)$ & $15(25.9)$ & & $1(4.8)$ & $58(32.6)$ & \\
\hline Moderately differentiated & $4(50.0)$ & $37(63.8)$ & & $11(52.4)$ & $108(60.7)$ & \\
\hline Poorly differentiated & $2(25.0)$ & $6(10.3)$ & & $9(42.9)$ & $12(6.7)$ & \\
\hline Lymphovascular invasion & & & 0.031 & & & 0.096 \\
\hline Absent & $4(50.0)$ & $50(86.2)$ & & $13(61.9)$ & $141(79.2)$ & \\
\hline Present & $4(50.0)$ & $8(13.8)$ & & $8(38.1)$ & $37(20.8)$ & \\
\hline Perineural invasion & & & 0.614 & & & 0.335 \\
\hline Absent & $7(87.5)$ & $52(89.7)$ & & $16(76.2)$ & $152(85.4)$ & \\
\hline Present & $1(12.5)$ & $6(10.3)$ & & $5(23.8)$ & $26(14.6)$ & \\
\hline Positive resection margin & & & 0.537 & & & 0.494 \\
\hline Absent & $4(50.0)$ & $32(55.2)$ & & $16(76.2)$ & $130(73.0)$ & \\
\hline Present & $4(50.0)$ & $26(44.8)$ & & $5(23.8)$ & $48(27.0)$ & \\
\hline Pathological T-classification & & & 0.365 & & & 0.238 \\
\hline pT1 & $3(37.5)$ & $29(50.0)$ & & $4(19.0)$ & $59(33.1)$ & \\
\hline pT2 & $4(50.0)$ & $18(31.0)$ & & $9(42.9)$ & $49(27.5)$ & \\
\hline pT3 & $0(0.0)$ & $10(17.2)$ & & $4(19.0)$ & $48(27.0)$ & \\
\hline pT4a & $1(9.1)$ & $1(1.7)$ & & $4(19.0)$ & $22(12.4)$ & \\
\hline Pathological N-classification & & & 0.012 & & & 0.003 \\
\hline pNO & $3(27.3)$ & $32(58.2)$ & & $6(28.6)$ & $105(59.0)$ & \\
\hline
\end{tabular}


Table 2 The status of FGFR1 gene amplification and protein overexpression in patients with hypopharyngeal and laryngeal squamous cell carcinoma (Continued)

\begin{tabular}{|c|c|c|c|c|c|c|}
\hline \multirow[t]{2}{*}{ Characteristics } & \multicolumn{2}{|c|}{ FGFR1 amplification, $n=66$} & \multirow{2}{*}{$\begin{array}{l}P \\
\text { value }\end{array}$} & \multicolumn{2}{|c|}{ FGFR1 high expression, $n=199$} & \multirow[t]{2}{*}{$P$ value } \\
\hline & Present, n (\%) & Absent, n (\%) & & Present, n (\%) & Absent, n (\%) & \\
\hline $\mathrm{pN1}$ & $0(0.0)$ & $4(7.3)$ & & $1(4.8)$ & $12(6.7)$ & \\
\hline pN2 & $1(9.1)$ & $7(12.7)$ & & $4(19.0)$ & $22(12.4)$ & \\
\hline pN3 & $7(63.6)$ & $12(21.8)$ & & $10(47.6)$ & 39 (21.9) & \\
\hline Pathological stage & & & 0.047 & & & 0.001 \\
\hline Stage I & $2(25.0)$ & $24(41.4)$ & & $1(4.8)$ & $53(29.8)$ & \\
\hline Stage II & $0(0.0)$ & $5(8.6)$ & & $3(14.3)$ & $26(14.6)$ & \\
\hline Stage III & $0(0.0)$ & $7(12.1)$ & & $2(9.5)$ & $30(16.9)$ & \\
\hline Stage IVA & $1(12.5)$ & $8(13.8)$ & & $5(23.8)$ & $30(16.9)$ & \\
\hline Stage IVB & $5(62.5)$ & $14(24.1)$ & & $10(47.6)$ & $39(21.9)$ & \\
\hline Recurrence & & & 0.042 & & & 0.263 \\
\hline No & $4(50.0)$ & $49(84.5)$ & & $14(66.7)$ & $141(79.2)$ & \\
\hline Yes & $4(50.0)$ & $9(15.5)$ & & $7(33.3)$ & $37(20.8)$ & \\
\hline Local recurrence only & $2(50.0)$ & $5(55.6)$ & & $2(28.6)$ & $20(54.1)$ & \\
\hline Distant recurrence & $2(50.0)$ & $4(44.4)$ & & $5(71.4)$ & $17(45.9)$ & \\
\hline
\end{tabular}

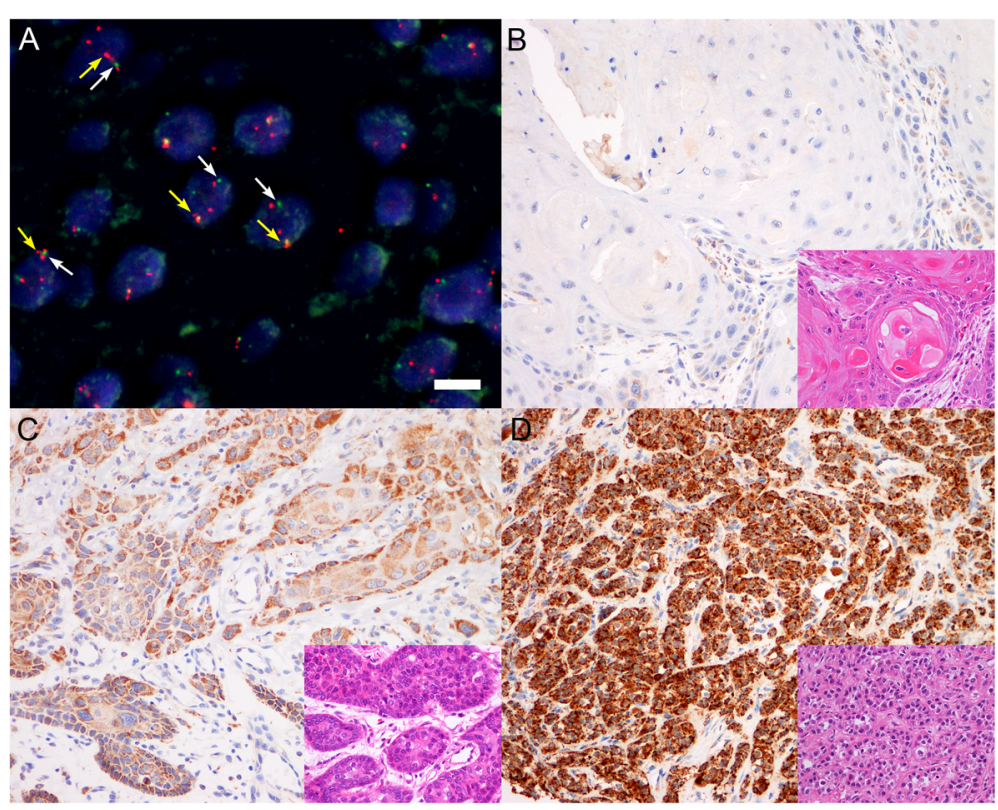

Fig. 1 FGFR1 FISH analysis and FGFR1 protein expression in hypopharyngeal and laryngeal squamous cell carcinoma (SCC). (a) Amplified FGFR1 expression is shown as red signals (yellow arrows) and CEP8 signal (white arrows) is shown as green in nuclei. Increased red signals (in number 3 6) compared to green signal (in number 1 2) could define amplification of FGFR1 gene. Scale bar represents $10 \mu m$. (original magnification, 1000x). Representative FGFR1 immunohistochemical staining (original magnification, 200x) showing negative (b), low expression (c), and high expression (d), and the corresponding hematoxylin and eosin-stained cases (inset; original magnification 400x) showing well differentiated SCC (b), moderately differentiated SCC (c), and poorly differentiated SCC (d) 
(12.1\%) patients displayed FGFR1 amplification (Table 2 and Fig. 1a). The mean FGFR1 copy number per nucleus and the mean FGFR1/CEP8 ratio in all patients were 2.37 (range, 1.85 to 6.75 copies per nucleus) and 1.00 (range, 0.42 to 2.54), respectively, in 66 tested cases. The mean FGFR1 copy number was 5.37 (range, 4.01 to 6.75 ) in the amplification group and 2.48 (range 1.85 to 4.86), in the non-amplification group. The mean FGFR1/CEP8 ratio was 2.23 (range 1.59 to 2.54 ) and 0.96 (range, 0.42 to 1.59$)$ in the amplification and non-amplification group, respectively (Supplementary Fig. 1).

The association of FGFR1 amplification with clinical and pathological factors is summarized in Table 2. FGFR1 amplification was more frequent in hypopharyngeal SCC than in laryngeal SCC $(6 / 42,14.3 \%$ versus $2 / 24,8.3 \% ; P=$ $0.015)$ and showed a significant correlation with the presence of lymphovascular invasion $(P=0.031)$, more advanced pathological $\mathrm{N}$-classification $(P=0.020)$, more advanced TNM tumor stage $(P=0.047)$, and more frequent recurrence rate $(P=0.042)$ than cases with no FGFR1 amplification. Other factors were not significant according to FGFR1 amplification status. For the 8 cases with FGFR1 amplified squamous cell carcinoma, the clinicopathologic characteristics as well as detailed status FGFR1 gene and FGFR1 protein are summarized in Supplementary Table S1.

\section{FGFR1 protein expression in hypopharyngeal and laryngeal SCC}

FGFR1 IHC was evaluable in 199 cases. FGFR1 staining exhibited cytoplasmic patterns with occasional weak nuclear patterns and was uniform in most tumor areas. The normal squamous epithelial cells and stromal cells adjacent to or separated from tumors were stained with an intensity from 0 to 2 , and none showed strong staining with an intensity score of 3. We found cases with predominantly strong FGFR1 staining intensity (score 3 ) in tumor cells, wherein positive staining was observed in more than $80 \%$ tumor cells; therefore, the $\mathrm{H}$-score of these cases was calculated to be more than 240 (Fig. 2a). Considering the expression pattern of FGFR1, we defined the cutoff value for high FGFR1 expression as a strong intensity and/or H-score of more than 240. The H-score of FGFR1 was only weakly correlated in stromal cells and tumor cells $(\mathrm{r}=0.256, P<0.001)$.

On the basis of the criteria of our series, 21 (10.6\%) patients showed high FGFR1 expression. The association between FGFR1 overexpression and clinical and pathological factors is summarized in Table 2. High FGFR1 expression was more frequently detected in poorly differentiated histology $(P<0.001$; Table 2 and Fig. 1b-d), while well differentiated SCC showed no or low FGFR1 expression (Fig. 2b). In comparison with no or low FGFR1 expression, high FGFR1 expression was associated with more advanced pathological N-classification $(P=0.003)$ and TNM stage $(P=0.001)$. Other factors were not significant according to FGFR1 expression status (Table 2). Consistent with FGFR1 gene expression, high FGFR1 protein expression showed a marginal tendency to be related with gene amplification, although no statistical significance was observed (Fig. 2c; $P=0.059$ ).

\section{Alteration of FGFR1 and epithelial mesenchymal transition (EMT)}

Snail and Twist IHC were evaluable in 67 cases. When comparing FGFR1 amplified SCC with non-amplified SCC, there were no statistically significant differences in Snail and Twist expression $(P=0.344$ and $P=0.637$, respectively; Supplementary Figure S2 and S3). The expression level of FGFR1 protein also did not correlate with the expression levels of Snail and Twist $(P=0.904$ and $P=$ 0.402, respectively; Supplementary Figure S2 and S3).

\section{Survival outcomes according to FGFR1 gene amplification and protein expression}

In the Kaplan-Meir analysis, patients with FGFR1 amplification were more associated with inferior DFS rate

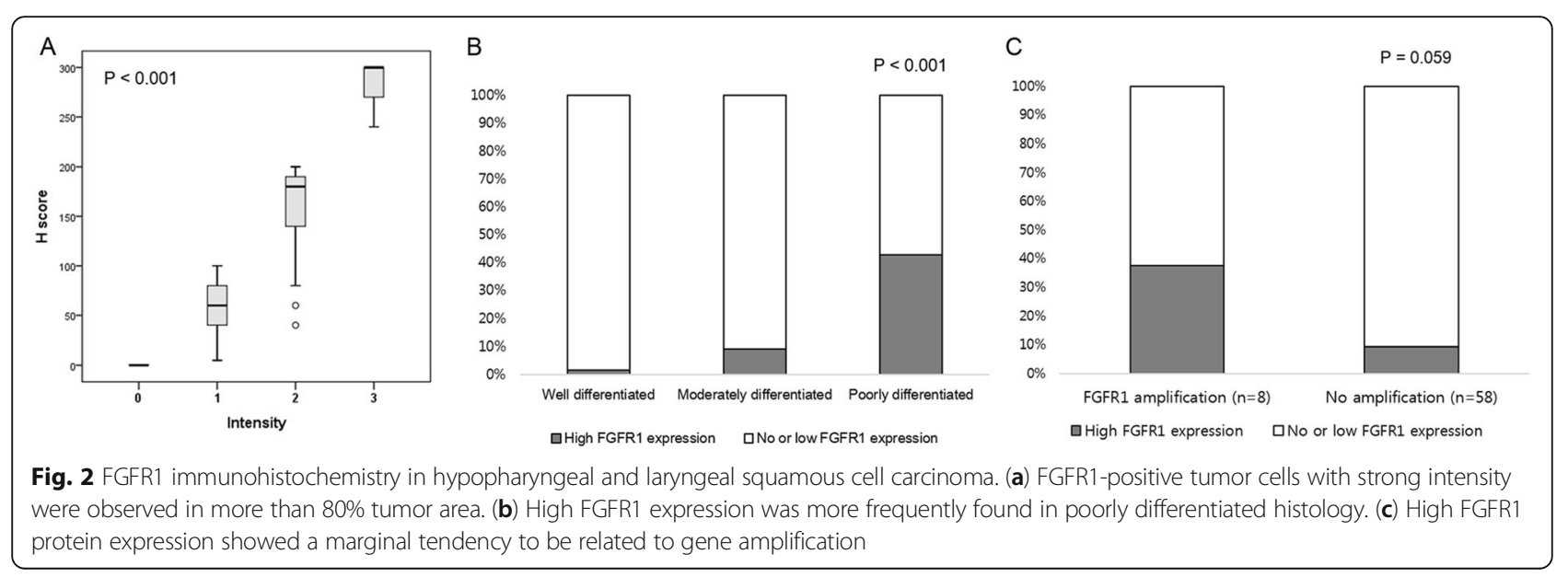


than those with no amplification $(P=0.010$, Fig. 3a); however, such significant association was not observed for OS rate $(P=0.240$, Fig. $3 \mathrm{~b})$. The status of FGFR1 protein expression showed no significant association with DFS and OS $(P=0.226$ and $P=0.341$, respectively; Fig. 3c and d).

In the univariate Cox proportional hazard analysis for DFS (Table 3), poorly differentiated histology (hazard ratio $[\mathrm{HR}] 3.803, P=0.006$ ), perineural invasion (HR 2.046, $P=0.039)$, pN-classification (N2; HR 5.415; $P<0.001$, N3; HR 2.816; $P=0.005$ ), pathologic stage (IV; HR 3.124; $P=0.007$ ), and FGFR1 amplification (HR 4.204, $P=$ $0.017)$ were significantly related to worse DFS. Of these, FGFR1 amplification was determined as an independent factor for poor DFS in multivariate analysis (HR 3.666, $P=0.049$ ).

In the univariate Cox proportional hazard analysis for OS (Table 4), older age ( $\geq 65$ years, HR 2.102, $P=0.009$ ), primary site (hypopharynx, HR 1.812, $P=0.042$ ), histologic differentiation (moderate; HR 2.885; $P=0.007$, poor; HR 3.180, $P=0.026$ ), lymphovascular invasion (HR 1.842, $P=0.040$ ), perineural invasion (HR 2.608, $P=$ 0.002 ), positive resection margin (HR 2.236, $P=0.006$ ), T-classification (T3; HR 1.715; $P=0.032$, T4a; HR 2.224;
$P=0.011)$, pN-classification (N2; HR 2.982; $P=0.005$, N3; HR 3.003; $P=0.001$ ), and advanced pathologic stage (III; HR 3.890; $P=0.011$, IV; HR 4.102; $P=0.004$ ) were significantly related to inferior OS rates. Older age $(\geq 65$ years, HR 1.835, $P=0.035$ ), positive resection margin (HR 2.712, $P=0.002$ ), and advanced pathologic stage (III; HR 3.018; $P=0.048$, IV; HR 2.967; $P=0.046$ ) were identified as the independent factors for poor OS in multivariate analysis.

\section{Discussion}

In the present study, we investigated the clinicopathologic and prognostic implications of FGFR1 gene amplification and protein overexpression in hypopharyngeal and laryngeal SCC. We analyzed a large number of cases that underwent standard management of curative surgery and appropriate adjuvant therapy in two different institutes.

In our series, hypopharyngeal and laryngeal SCCs were generally detected in late adulthood, and frequently related to smoking and alcohol consumption and p16 IHC negativity. Furthermore, advanced tumor stages, especially advanced pathologic lymph node stages, were not uncommon, and the 5-year DFS and OS rates were 74.1
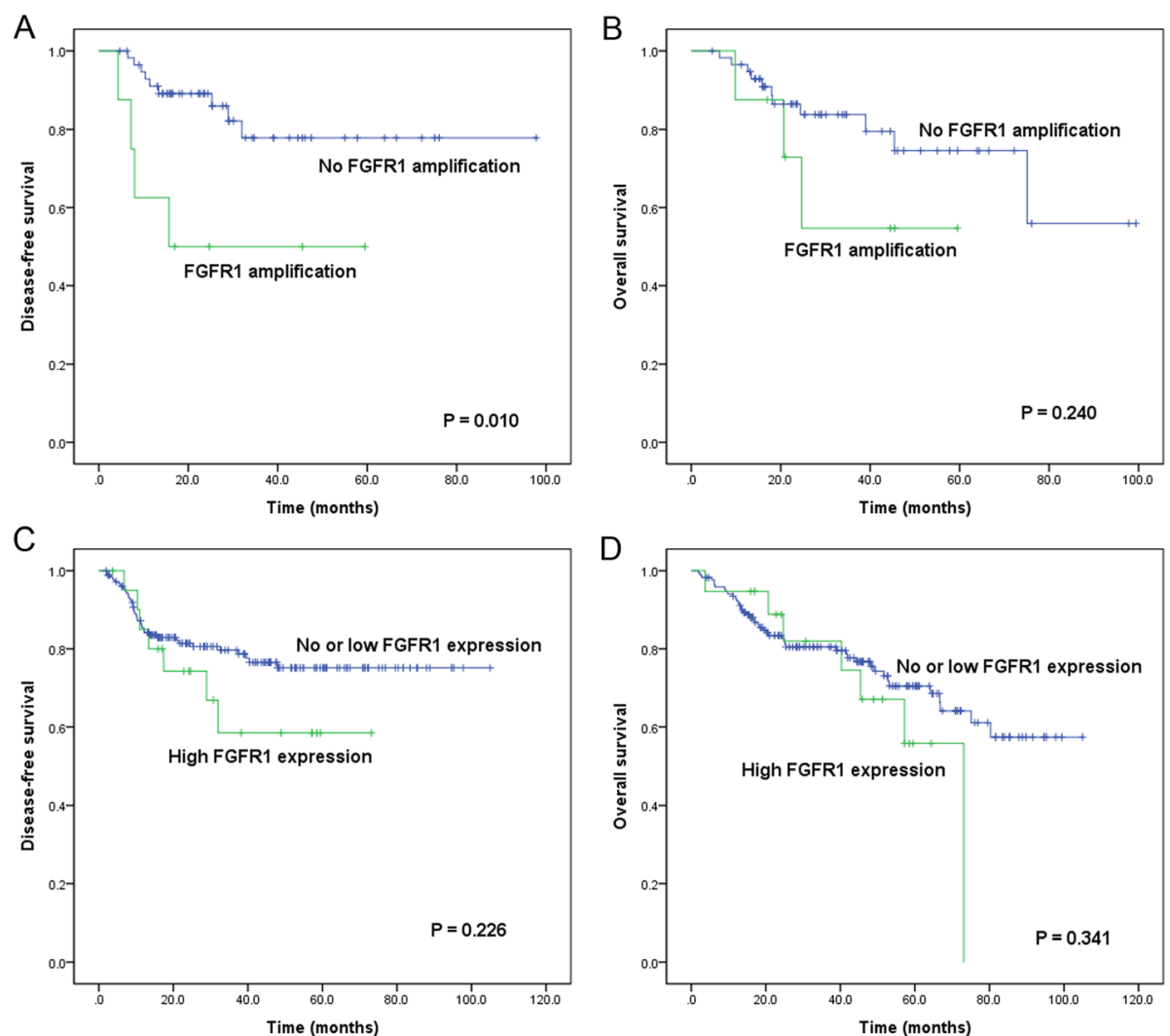

Fig. 3 Kaplan-Meier survival curves for FGFR1 gene amplification ( $\mathbf{a}$ and $\mathbf{b}$ ) and protein overexpression (c and $\mathbf{d}$ ) in hypopharyngeal and laryngeal squamous cell carcinoma. FGFR1 amplification was significantly associated with disease-free survival (a) but not overall survival (b). FGFR1 protein overexpression was not related to disease-free survival (c) or overall survival (d) 
Table 3 Cox proportional hazards regression model for disease-free survival in hypopharyngeal and laryngeal squamous cell carcinoma

\begin{tabular}{|c|c|c|c|c|}
\hline \multirow[t]{2}{*}{ Variables } & \multicolumn{2}{|l|}{ Univariate } & \multicolumn{2}{|c|}{ Multivariate } \\
\hline & $P$ value & HR $(95 \% \mathrm{Cl})$ & $P$ value & HR $(95 \% \mathrm{Cl})$ \\
\hline$\geq 65$ years & 0.485 & $1.232(0.686-2.211)$ & & \\
\hline Male & 0.961 & $1.030(0.319-3.324)$ & & \\
\hline \multicolumn{5}{|l|}{ Primary sites } \\
\hline Larynx & & 1 (reference) & & \\
\hline Hypopharynx & 0.385 & $1.331(0.698-2.536)$ & & \\
\hline \multicolumn{5}{|l|}{ Smoking } \\
\hline Never smoker & & 1 (reference) & & \\
\hline Smoker & 0.368 & $0.690(0.308-1.546)$ & & \\
\hline \multicolumn{5}{|l|}{ Alcohol } \\
\hline Non- or social- drinker & & 1 (reference) & & \\
\hline Heavy drinker & 0.196 & $1.763(0.746-4.164)$ & & \\
\hline \multicolumn{5}{|l|}{ Differentiation } \\
\hline Well & & 1 (reference) & & 1 (reference) \\
\hline Moderate & 0.057 & $2.148(0.979-4.715)$ & 0.687 & $1.340(0.323-5.561)$ \\
\hline Poor & 0.006 & 3.803 (1.466-9.864) & 0.883 & $1.154(0.170-7.839)$ \\
\hline Lymphovascular invasion & 0.120 & $1.669(0.875-3.180)$ & & \\
\hline Perineural invasion & 0.039 & $2.046(1.035-4.040)$ & 0.613 & $0.567(0.063-5.119)$ \\
\hline Positive resection margin & 0.091 & $1.710(0.919-3.185)$ & & \\
\hline \multicolumn{5}{|l|}{ pT-classification } \\
\hline pT1 & & 1 (reference) & & \\
\hline pT2 & 0.906 & $1.051(0.463-2.384)$ & & \\
\hline pT3 & 0.178 & 1.715 (0.782-3.759) & & \\
\hline pT4a & 0.070 & $2.224(0.936-5.282)$ & & \\
\hline \multicolumn{5}{|l|}{ pN-classification } \\
\hline pNO & & 1 (reference) & & \\
\hline pN1 & 0.062 & $2.881(0.948-8.757)$ & & \\
\hline pN2 & $<0.001$ & $5.415(2.492-11.769)$ & & \\
\hline pN3 & 0.005 & $2.816(1.359-5.837)$ & & \\
\hline \multicolumn{5}{|l|}{ Pathological stage } \\
\hline Stage I & & 1 (reference) & & 1 (reference) \\
\hline Stage ॥ & 0.686 & $0.756(0.195-2.929)$ & 0.904 & $1.147(0.124-10.594)$ \\
\hline Stage III & 0.168 & $2.089(0.732-5.960)$ & 0.982 & $<0.001$ \\
\hline Stage IV & 0.007 & $3.124(1.364-7.153)$ & 0.234 & $2.511(0.551-11.438)$ \\
\hline Adjuvant treatment & 0.396 & $1.303(0.707-2.400)$ & & \\
\hline p16 positivity & 0.791 & $1.073(0.637-1.806)$ & & \\
\hline FGFR1 amplification & 0.017 & $4.204(1.290-13.698)$ & 0.049 & $3.666(1.006-13.361)$ \\
\hline FGFR1 high expression & 0.235 & $1.633(0.727-3.664)$ & & \\
\hline
\end{tabular}

${ }^{a}$ Abbreviations: $\mathrm{Cl}$ Confidence interval, $H R$ Hazard ratio

${ }^{\mathrm{b}}$ Variables of the $\mathrm{pT}$ and $\mathrm{pN}$ classification were not included in the multivariate analysis, because they were included in the pathologic stage

and $67.6 \%$, respectively, indicating that a proportion of patients with this disease exhibited unfavorable outcomes. These demographic features were generally similar to those previously reported and our series may be used as a surrogate of the population-based data [30, 31]. Hypopharyngeal SCCs showed more lymph node metastasis compared to laryngeal SCC in our study and they were expected to have a worse prognosis than 
Table 4 Cox proportional hazards regression model for overall survival in hypopharyngeal and laryngeal squamous cell carcinoma

\begin{tabular}{|c|c|c|c|c|}
\hline \multirow[t]{2}{*}{ Variables } & \multicolumn{2}{|c|}{ Univariate } & \multicolumn{2}{|c|}{ Multivariate } \\
\hline & $P$ value & HR $(95 \% \mathrm{Cl})$ & $P$ value & HR $(95 \% \mathrm{Cl})$ \\
\hline$\geq 65$ years & 0.009 & $2.102(1.207-3.663)$ & 0.035 & $1.835(1.042-3.231)$ \\
\hline Male & 0.503 & $1.493(0.463-4.816)$ & & \\
\hline \multicolumn{5}{|l|}{ Primary sites } \\
\hline Larynx & & 1 (reference) & & 1 (reference) \\
\hline Hypopharynx & 0.042 & $1.812(1.022-3.213)$ & 0.702 & $1.142(0.580-2.248)$ \\
\hline \multicolumn{5}{|l|}{ Smoking } \\
\hline Never smoker & & 1 (reference) & & \\
\hline Smoker & 0.621 & $1.263(0.500-3.190)$ & & \\
\hline \multicolumn{5}{|l|}{ Alcohol } \\
\hline Non- or social- drinker & & 1 (reference) & & \\
\hline Heavy drinker & 0.160 & $1.772(0.798-3.937)$ & & \\
\hline \multicolumn{5}{|l|}{ Differentiation } \\
\hline Well & & 1 (reference) & & 1 (reference) \\
\hline Moderate & 0.007 & 2.885 (1.343-6.199) & 0.033 & $2.422(1.076-5.452)$ \\
\hline Poor & 0.026 & 3.180 (1.147-8.819) & 0.422 & $1.398(0.532-4.513)$ \\
\hline Lymphovascular invasion & 0.040 & $1.842(1.029-3.296)$ & 0.569 & $0.819(0.411-1.632)$ \\
\hline Perineural invasion & 0.002 & $2.608(1.411-4.821)$ & 0.098 & $1.825(0.896-3.720)$ \\
\hline Positive resection margin & 0.006 & $2.236(1.265-3.951)$ & 0.002 & $2.712(1.425-5.161)$ \\
\hline \multicolumn{5}{|l|}{ pT-classification } \\
\hline pT1 & & 1 (reference) & & \\
\hline pT2 & 0.358 & $1.464(0.649-3.301)$ & & \\
\hline pT3 & 0.032 & $1.715(1.076-5.171)$ & & \\
\hline pT4a & 0.011 & $2.224(1.286-6.928)$ & & \\
\hline \multicolumn{5}{|l|}{ pN-classification } \\
\hline pNO & & 1 (reference) & & \\
\hline $\mathrm{pN1}$ & 0.085 & $2.385(0.888-6.409)$ & & \\
\hline pN2 & 0.005 & $2.982(1.382-6.431)$ & & \\
\hline pN3 & 0.001 & $3.003(1.578-5.714)$ & & \\
\hline \multicolumn{5}{|l|}{ Pathological stage } \\
\hline Stage I & & 1 (reference) & & 1 (reference) \\
\hline Stage ॥ & 0.482 & $1.561(0.451-5.402)$ & 0.457 & $1.625(0.452-5.847)$ \\
\hline Stage III & 0.011 & $3.890(1.361-11.117)$ & 0.048 & 3.018 (1.010-9.018) \\
\hline Stage IV & 0.004 & $4.102(1.591-10.581)$ & 0.046 & $2.967(1.018-8.647)$ \\
\hline Adjuvant treatment & 0.615 & $1.154(0.661-2.013)$ & & \\
\hline p16 positivity & 0.127 & $0.331(0.080-1.368)$ & & \\
\hline FGFR1 amplification & 0.252 & $2.128(0.585-7.738)$ & & \\
\hline FGFR1 high expression & 0.319 & $1.504(0.674-3.354)$ & & \\
\hline
\end{tabular}

abbreviations: Cl Confidence interval, HR Hazard ratio

${ }^{b}$ Variables of the $\mathrm{pT}$ and $\mathrm{pN}$ classification were not included in the multivariate analysis, because they were included in the pathologic stage

laryngeal SCC. However, in Kaplan-Meier analysis and multivariate Cox regression model, the difference between OS and DFS according to larynx and hypopharynx was not statistically significant. Therefore, we think combining these two groups would not cause serious selection bias, but the concept of non-HPV related SCC can be approached.

FGFR1 gene amplification was observed in about 12\% tested hypopharyngeal and laryngeal SCC cases that was slightly more frequent in hypopharyngeal SCC (14.3\%) 
than in laryngeal SCC (8.3\%). FGFR1 amplification has been suggested as an oncogenic driver mutation in tobacco-associated cancers of the aerodigestive tract [16, 32-34]. Previous studies on FGFR1 in HNSCC have shown that FGFR1 amplification is more common in the SCC of hypopharynx and larynx than in that of oropharynx or oral cavity $[14,16]$. In addition, FGFR1 amplification has no relationship with HPV infection [13]. All these findings are suggestive of the biological role of FGFR1 amplification in the tumorigenesis of these tobacco or alcohol-related cancers, hypopharyngeal and laryngeal SCCs, and may predict the role of targeted therapy for these tumors [30,31].

Considering the clinical implications of FGFR1 amplification, we observed significant association with poor prognostic factors, specifically, lymphovascular invasion and advanced stages of lymph node metastasis. This observation may be related to our findings that cases with FGFR1 amplification were closely associated with advanced TNM tumor stages and poorer DFS. In particular, FGFR1 amplification was determined as an independent factor for disease progression and thus, may be involved in the invasion, metastasis, and drug resistance of tumor cells during the development of treatment-resistant, aggressive, advanced hypopharyngeal and laryngeal SCCs. Several studies have also shown that FGFR1 amplification plays a role in the invasion, metastasis, and drug resistance of various tumors $[32,35]$. A recent study performed genomic profiling of HNSCC using targeted next-generation sequencing and identified FGFR1 amplification as an independent prognostic factor for OS [14], while it has been failed to impact on prognosis in other studies $[15,16,36]$. In our study, we failed to detect any association between FGFR1 amplification and OS. Cases positive for FGFR1 amplification were relatively fewer in number in previous and present studies; therefore, its prognostic role warrants validation in future studies, including meta-analysis.

In our series, high FGFR1 expression was observed in about $11 \%$ of tested cases with hypopharynx and larynx SCCs. Similar to FGFR1 amplification, FGFR1 protein overexpression was associated with lymph node metastasis and advanced TNM tumor stages. Considering the marginal association between high FGFR1 expression and FGFR1 amplification, gene amplification and the subsequent protein overexpression may be one of the related mechanisms underlying the invasion and metastasis of hypopharyngeal and laryngeal SCCs. However, FGFR1 protein overexpression showed no effect on survival outcomes. Previous studies have shown a disagreement with prognostic values of FGFR1 overexpression in HNSCC, probably owing to the use of different FGFR1 overexpression criteria, anti-FGFR1 antibodies, and cohorts with different anatomical locations $[13,17,37]$.
FGFR1 demonstrated strong and diffused expression in poorly differentiated SCC, while normal, dysplastic squamous epithelium, or well differentiated SCC exhibited weak to moderate expression patterns. In a recent study on oral tongue SCC, FGFR1 expression was stronger in high-grade dysplasia than in low-grade dysplasia as well as in the nucleus of poorly differentiated SCC cells [37]. However, we failed to report any increase in nuclear staining in poorly differentiated SCC. These results suggest that FGFR1 may be one of the important factors in the carcinogenesis and progression of HPVnegative, smoking- and alcohol-related SCC represented by hypopharyngeal and laryngeal SCC.

Regarding the biologic implications of FGFR1 gene amplification or protein overexpression in hypopharyngeal and laryngeal SCC, we investigated a correlation of FGFR1 alteration with twist and snail, the well-known EMT markers, on the basis of previous studies showing that EMT is induced in tumors by abnormal activation of the FGFR signaling pathway in several types of cancers including HNSCC [38-41]. However, we did not observe that amplification or high protein expression of FGFR1 is related to overexpression of these two EMT-related proteins. Therefore, further studies are needed to determine whether changes in FGFR1 affect EMT acquisition in hypopharyngeal and laryngeal SCC. In addition, further in-depth studies should be followed for the underlying mechanisms of aberrant FGFR1 alterations in the tumorigenesis of hypopharyngeal and laryngeal SCC in the aspect of the known downstream signals of RAS/MAPK, PI3K/ AKT, and JAK/STAT signaling pathways [11].

FGFR1 gene amplification and protein or mRNA expression have demonstrated correlation in some previous studies [23, 28]. However, we could not find any strong correlation between FGFR1 gene amplification and protein overexpression. This discrepancy may be associated with the differences in the cutoff level of amplification and protein or mRNA expression among various studies. Furthermore, FGFR1 amplification may not always cause protein overexpression alone, and may be affected by other closely related receptor tyrosine kinases (RTK). In lung SCC, some researchers suggested the mechanism of discrepancy between protein expression and gene amplification of FGFR1 due to crosstalk between FGFR1 and co-activated RTKs in FGFR1amplified lung cancers with low FGFR1 protein expression $[42,43]$.

\section{Conclusions}

In summary, we report that FGFR1 gene amplification and protein overexpression occur in hypopharyngeal and laryngeal SCC with an incidence of 12.1 and $10.6 \%$, respectively. High FGFR1 expression was more frequent with the worsening of histologic differentiation. In 
addition, FGFR1 amplification appeared as an independent prognostic factor for DFS and may serve as a prognostic biomarker. These results suggest that the altered FGFR1 pathways play an important role in the malignant evolution and progression of hypopharyngeal and laryngeal SCC. Several emerging FGFR1-targeted therapies may shed light on treatment of patients with hypopharyngeal and laryngeal SCC that usually lack specific therapeutic targets.

\section{Supplementary information}

Supplementary information accompanies this paper at https://doi.org/10. 1186/s12885-020-06792-7.

Additional file 1: Figure S1. The mean FGFR1/CEP8 ratio (R) and the mean FGFR1 copy number (CN) in hypopharyngeal and laryngeal squamous cell carcinoma. (A) The mean FGFR1 R and CN were 2.37 and 1.00, respectively, in 66 tested cases. (B) The mean FGFR1 R was 2.18 and 0.96 in the amplification and non-amplification group, respectively. (C) The mean FGFR1 CN was 5.36 in the amplification group and 2.48, in the non-amplification group.

Additional file 2: Figure S2. The box-plot graphs of Snail (A and C) and Twist (B and $\mathrm{D}$ ) immunohistochemical analysis ( $\mathrm{H}$-score) of protein expression in hypopharyngeal and laryngeal SCC. There is no statistically significant differences in Snail and Twist expression according to FGFR1 amplification ( $P=0.344$ and $P=0.637$, respectively; $A$ and $B$ ) or high protein expression ( $P=0.904$ and $P=0.402$, respectively; $C$ and $D)$.

Additional file 3: Figure S3. Snail (A-C) and Twist (D-F) protein expression by immunohistochemical staining in hypopharyngeal and laryngeal SCC. They both show nuclear staining. (A and D) Negative/ weak, ( $\mathrm{B}$ and $\mathrm{E}$ ) moderate, and ( $\mathrm{C}$ and $\mathrm{F}$ ) strong intensities.

Additional file 4: Table S1. Clinicopathologic characteristics of 8 cases of FGFR1 amplified squamous cell carcinoma.

\section{Abbreviations}

AKT: Protein kinase B; CEP8: Chromosome 8; Cl: Confidence interval; DFS: Disease-free survival; EGFR: Epidermal growth factor receptor; FGFR1: Fibroblast growth factor receptor 1; FISH: Fluorescence in situ hybridization; FFPE: Formalin-fixed, paraffin-embedded; HNSCC: Head and neck squamous cell carcinoma; HPV: Human papilloma virus;

IHC: Immunohistochemistry; HR: Hazard ratio; JAK: Janus kinase; AJCC: Joint Committee on Cancer; MAPK: Mitogen-activated protein kinase; OS: Overall survival; STAT: Signal transducer and activator of transcription;

SCC: Squamous cell carcinoma; TCGA: The Cancer Genome Atlas; TMA: Tissue microarray

\section{Acknowledgements}

Not applicable.

\section{Authors' contributions}

Study concepts \& design: BCC and SOY. Construction of material and database: YWK, HAS, YAC. Data analysis and interpretation: EKK and SOY. Statistical analysis and manuscript preparation: EKK. Manuscript review and editing: SOY, BCC, YWK, and HAS. All authors reviewed and accepted the final version of the manuscript.

\section{Funding}

The study was supported by National Health Insurance Service Ilsan Hospital grant (NHIMC2018CR043). The funding bodies had no role in the design of the study and collection, analysis, interpretation of data, and in writing the manuscript.

\section{Availability of data and materials}

The datasets used and/or analyzed during the current study are available from the corresponding author on reasonable request.

\section{Ethics approval and consent to participate}

This retrospective study was approved by the Institutional Review Board of Severance Hospital (4-2015-0954) and National Health Insurance Service llsan Hospital (NHIMC 2018-04-021). Informed consent was waived owing to the retrospective nature of this study.

\section{Consent for publication}

Not applicable.

\section{Competing interests}

The authors declare that they have no competing interests.

\section{Author details}

'Department of Pathology, National Health Insurance Service Ilsan Hospital, Goyang 10444, South Korea. ${ }^{2}$ Department of Pathology, Severance Hospital, Yonsei University College of Medicine, 50-1 Yonsei-ro, Seodaemun-gu, Seoul 03722, South Korea. ${ }^{3}$ Department of Pathology and Translational genomics, Samsung Medical Center, Seoul 06351, South Korea. ${ }^{4}$ Department of Otorhinolaryngology, Severance Hospital, Yonsei University College of Medicine, Seoul 03722, South Korea. ${ }^{5}$ Department of

Otorhinolaryngology-Head Neck Surgery, National Health Insurance Service Ilsan Hospital, Goyang 10444, South Korea. ${ }^{6}$ Division of Medical Oncology, Yonsei Cancer Center, Yonsei University College of Medicine, 50-1 Yonsei-ro, Seodaemun-gu, Seoul 03722, South Korea.

Received: 30 August 2019 Accepted: 26 March 2020

Published online: 18 April 2020

\section{References}

1. Hashibe M, Brennan P, Benhamou S, Castellsague X, Chen C, Curado MP, Dal Maso L, Daudt AW, Fabianova E, Fernandez L, et al. Alcohol drinking in never users of tobacco, cigarette smoking in never drinkers, and the risk of head and neck cancer: pooled analysis in the international head and neck Cancer epidemiology consortium. J Natl Cancer Inst. 2007;99(10):777-89.

2. El-Naggar AK, Chan JKC, Grandis JR, Takata T, Slootweg PJ. WHO classification of head and neck Tumours. 4th ed. Lyon: International Agency for Research on Cancer; 2017.

3. Gillison ML, D'Souza G, Westra W, Sugar E, Xiao W, Begum S, Viscidi R. Distinct risk factor profiles for human papillomavirus type 16-positive and human papillomavirus type 16-negative head and neck cancers. J Natl Cancer Inst. 2008;100(6):407-20.

4. Ang KK, Harris J, Wheeler R, Weber R, Rosenthal DI, Nguyen-Tan PF, Westra WH, Chung $\mathrm{CH}$, Jordan RC, Lu C, et al. Human papillomavirus and survival of patients with oropharyngeal cancer. N Engl J Med. 2010;363(1):24-35.

5. Posner MR, Lorch JH, Goloubeva O, Tan M, Schumaker LM, Sarlis NJ, Haddad RI, Cullen KJ. Survival and human papillomavirus in oropharynx cancer in TAX 324: a subset analysis from an international phase III trial. Ann Oncol. 2011;22(5):1071-7.

6. Lewis JS JJ, Ukpo OC, Ma XJ, Flanagan JJ, Luo Y, Thorstad WL, Chernock RD. Transcriptionally-active high-risk human papillomavirus is rare in oral cavity and laryngeal/hypopharyngeal squamous cell carcinomas--a tissue microarray study utilizing E6/E7 mRNA in situ hybridization. Histopathology. 2012;60(6):982-91.

7. Bray F, Ferlay J, Soerjomataram I, Siegel RL, Torre LA, Jemal A. Global cancer statistics 2018: GLOBOCAN estimates of incidence and mortality worldwide for 36 cancers in 185 countries. CA Cancer J Clin. 2018;68(6):394-424.

8. Chaturvedi AK, Engels EA, Pfeiffer RM, Hernandez BY, Xiao W, Kim E, Jiang B, Goodman MT, Sibug-Saber M, Cozen W, et al. Human papillomavirus and rising oropharyngeal cancer incidence in the United States. J Clin Oncol. 2011;29(32):4294-301.

9. Cancer Genome Atlas Network. Comprehensive genomic characterization of head and neck squamous cell carcinomas. Nature. 2015:517(7536):576-82.

10. Hallinan N, Finn S, Cuffe S, Rafee S, O'Byrne K, Gately K. Targeting the fibroblast growth factor receptor family in cancer. Cancer Treat Rev. 2016;46: 51-62.

11. Brooks AN, Kilgour E, Smith PD. Molecular pathways: fibroblast growth factor signaling: a new therapeutic opportunity in cancer. Clin Cancer Res. 2012;18(7):1855-62.

12. Freier $\mathrm{K}$, Schwaenen $\mathrm{C}$, Sticht $\mathrm{C}$, Flechtenmacher $\mathrm{C}$, Muhling J, Hofele $\mathrm{C}$, Radlwimmer B, Lichter P, Joos S. Recurrent FGFR1 amplification and high 
FGFR1 protein expression in oral squamous cell carcinoma (OSCC). Oral Oncol. 2007;43(1):60-6.

13. Koole K, Brunen D, van Kempen PM, Noorlag R, de Bree R, Lieftink C, van Es RJ, Bernards R, Willems SM. FGFR1 is a potential prognostic biomarker and therapeutic target in head and neck squamous cell carcinoma. Clin Cancer Res. 2016;22(15):3884-93.

14. Dubot C, Bernard V, Sablin MP, Vacher S, Chemlali W, Schnitzler A, Pierron G,

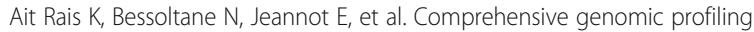
of head and neck squamous cell carcinoma reveals FGFR1 amplifications and tumour genomic alterations burden as prognostic biomarkers of survival. Eur J Cancer. 2018;91:47-55.

15. Clauditz TS, Böttcher A, Hanken H, Borgmann K, Sauter G, Wilczak W, Grob T, Münscher A. Prevalence of fibroblast growth factor receptor 1 (FGFR1) amplification in squamous cell carcinomas of the head and neck. J Cancer Res Clin Oncol. 2018;144(1):53-61.

16. Goke F, Bode M, Franzen A, Kirsten R, Goltz D, Goke A, Sharma R, Boehm D, Vogel W, Wagner $P$, et al. Fibroblast growth factor receptor 1 amplification is a common event in squamous cell carcinoma of the head and neck. Mod Pathol. 2013;26(10):1298-306.

17. Koole K, Clausen MJ, van Es RJ, van Kempen PM, Melchers LJ, Koole R, Langendijk JA, van Diest PJ, Roodenburg JL, Schuuring E, et al. FGFR family members protein expression as prognostic markers in Oral cavity and Oropharyngeal squamous cell carcinoma. Mol Diagn Ther. 2016;20(4):363-74.

18. Ipenburg NA, Koole K, Liem KS, van Kempen PM, Koole R, van Diest PJ, van Es RJ, Willems SM. Fibroblast growth factor receptor family members as prognostic biomarkers in head and neck squamous cell carcinoma: a systematic review. Target Oncol. 2016;11(1):17-27.

19. Lim SH, Sun JM, Choi YL, Kim HR, Ahn S, Lee JY, Lee SH, Ahn JS, Park K, Kim $J$, et al. Efficacy and safety of dovitinib in pretreated patients with advanced squamous non-small cell lung cancer with FGFR1 amplification: a single-arm, phase 2 study. Cancer. 2016;122(19):3024-31.

20. Hashemi-Sadraei N, Hanna N. Targeting FGFR in squamous cell carcinoma of the lung. Target Oncol. 2017;12(6):741-55.

21. Andre F, Cortes J. Rationale for targeting fibroblast growth factor receptor signaling in breast cancer. Breast Cancer Res Treat. 2015;150(1):1-8.

22. Touat M, lleana E, Postel-Vinay S, Andre F, Soria JC. Targeting FGFR signaling in Cancer. Clin Cancer Res. 2015;21(12):2684-94.

23. Goke F, Franzen A, Hinz TK, Marek LA, Yoon P, Sharma R, Bode M, von Maessenhausen A, Lankat-Buttgereit B, Goke A, et al. FGFR1 expression levels predict BGJ398 sensitivity of FGFR1-dependent head and neck squamous cell cancers. Clin Cancer Res. 2015;21(19):4356-64.

24. Specenier $P$, Vermorken JB. Cetuximab in the treatment of squamous cell carcinoma of the head and neck. Expert Rev Anticancer Ther. 2011;11(4): 511-24.

25. Amin MBESB. AJCC cancer staging manual / American Joint Committee on Cancer. 8th ed. New York: Springer; 2017.

26. Couraud S, Zalcman G, Milleron B, Morin F, Souquet PJ. Lung cancer in never smokers--a review. Eur J Cancer. 2012;48(9):1299-311.

27. Kim K, Kim JS. The association between alcohol consumption patterns and health-related quality of life in a nationally representative sample of south Korean adults. PLoS One. 2015;10(3):e0119245.

28. Zhang L, Yu H, Badzio A, Boyle TA, Schildhaus HU, Lu X, Dziadziuszko R, Jassem J, Varella-Garcia M, Heasley LE, et al. Fibroblast growth factor receptor 1 and related ligands in small-cell lung Cancer. J Thorac Oncol. 2015;10(7):1083-90.

29. Fakhry C, Lacchetti C, Rooper LM, Jordan RC, Rischin D, Sturgis EM, Bell D, Lingen MW, Harichand-Herdt S, Thibo J, et al. Human papillomavirus testing in head and neck carcinomas: ASCO clinical practice guideline endorsement of the College of American Pathologists Guideline. J Clin Oncol. 2018;36(31): 3152-61.

30. Carvalho AL, Nishimoto IN, Califano JA, Kowalski LP. Trends in incidence and prognosis for head and neck cancer in the United States: a site-specific analysis of the SEER database. Int J Cancer. 2005;114(5):806-16.

31. Gatta G, Botta L, Sanchez MJ, Anderson LA, Pierannunzio D, Licitra L. Prognoses and improvement for head and neck cancers diagnosed in Europe in early 2000s: the EUROCARE-5 population-based study. Eur J Cancer. 2015;51(15):2130-43.

32. Weiss J, Sos ML, Seidel D, Peifer M, Zander T, Heuckmann JM, Ullrich RT, Menon R, Maier S, Soltermann A, et al. Frequent and focal FGFR1 amplification associates with therapeutically tractable FGFR1 dependency in squamous cell lung cancer. Sci Transl Med. 2010;2(62):62ra93.
33. Kim HR, Kim DJ, Kang DR, Lee JG, Lim SM, Lee CY, Rha SY, Bae MK, Lee YJ, Kim SH, et al. Fibroblast growth factor receptor 1 gene amplification is associated with poor survival and cigarette smoking dosage in patients with resected squamous cell lung cancer. J Clin Oncol. 2013;31(6):731-7.

34. Kim HS, Lee SE, Bae YS, Kim DJ, Lee CG, Hur J, Chung H, Park JC, Jung DH, Shin SK, et al. Fibroblast growth factor receptor 1 gene amplification is associated with poor survival in patients with resected esophageal squamous cell carcinoma. Oncotarget. 2015;6(4):2562-72.

35. Turner N, Pearson A, Sharpe R, Lambros M, Geyer F, Lopez-Garcia MA, Natrajan R, Marchio C, lorns E, Mackay A, et al. FGFR1 amplification drives endocrine therapy resistance and is a therapeutic target in breast cancer. Cancer Res. 2010;70(5):2085-94.

36. Monico J, Miller B, Rezeanu L, May W, Sullivan DC. Fibroblast growth factor receptor 1 amplification in laryngeal squamous cell carcinoma. PLoS One. 2018;13(1):e0186185

37. Mariz B, Soares CD, de Carvalho MGF, Jorge-Junior J. FGF-2 and FGFR-1 might be independent prognostic factors in oral tongue squamous cell carcinoma. Histopathology. 2019;74(2):311-20.

38. Nguyen PT, Tsunematsu T, Yanagisawa S, Kudo Y, Miyauchi M, Kamata N, Takata T. The FGFR1 inhibitor PD173074 induces mesenchymal-epithelial transition through the transcription factor AP-1. Br J Cancer. 2013;109(8): 2248-58

39. Osada AH, Endo K, Kimura Y, Sakamoto K, Nakamura R, Sakamoto K, Ueki K, Yoshizawa K, Miyazawa K, Saitoh M. Addiction of mesenchymal phenotypes on the FGF/FGFR axis in oral squamous cell carcinoma cells. PLoS One. 2019;14(11):e0217451.

40. Brown WS, Akhand SS, Wendt MK. FGFR signaling maintains a drug persistent cell population following epithelial-mesenchymal transition. Oncotarget. 2016;7(50):83424-36.

41. Tomlinson DC, Baxter EW, Loadman PM, Hull MA, Knowles MA. FGFR1induced epithelial to mesenchymal transition through MAPK/PLCgamma/ COX-2-mediated mechanisms. PLoS One. 2012;7(6):e38972.

42. Kotani H, Ebi H, Kitai H, Nanjo S, Kita K, Huynh TG, Ooi A, Faber AC, MinoKenudson M, Yano S. Co-active receptor tyrosine kinases mitigate the effect of FGFR inhibitors in FGFR1-amplified lung cancers with low FGFR1 protein expression. Oncogene. 2016;35(27):3587-97.

43. Adachi Y, Watanabe K, Kita K, Kitai H, Kotani H, Sato Y, Inase N, Yano S, Ebi $H$. Resistance mediated by alternative receptor tyrosine kinases in FGFR1amplified lung cancer. Carcinogenesis. 2017;38(11):1063-72.

\section{Publisher's Note}

Springer Nature remains neutral with regard to jurisdictional claims in published maps and institutional affiliations.

Ready to submit your research? Choose BMC and benefit from

- fast, convenient online submission

- thorough peer review by experienced researchers in your field

- rapid publication on acceptance

- support for research data, including large and complex data types

- gold Open Access which fosters wider collaboration and increased citations

- maximum visibility for your research: over $100 \mathrm{M}$ website views per year

At BMC, research is always in progress.

Learn more biomedcentral.com/submissions 